\title{
Critical appraisal of pazopanib as treatment for patients with advanced metastatic renal cell carcinoma
}

This article was published in the following Dove Press journal:

Cancer Management and Research

9 August 20II

Number of times this article has been viewed

\author{
Ronald M Bukowski \\ Cleveland Clinic Taussig Cancer \\ Center, Cleveland Clinic Foundation, \\ Cleveland, OH, USA
}

\begin{abstract}
The management of renal cell carcinoma (RCC) has undergone significant changes during the past 10 years, with the treatment of metastatic RCC undergoing the most radical changes. These developments reflect an enhanced understanding of this tumor's underlying biology, which was then translated into the development of a new treatment paradigm. Current therapeutic approaches for the management of patients with metastatic RCC utilize knowledge of histology, molecular abnormalities, clinical prognostic factors, the natural history of this malignancy, and the treatment efficacy and toxicity of available agents. The treatment options available for patients with metastatic RCC have changed dramatically over the past 6 years. Interferon- $\alpha$ and interleukin- 2 were the previous mainstays of therapy, but since December 2005, six new agents have been approved in the US for the treatment of advanced RCC. Three are multi-targeted tyrosine kinase inhibitors (TKI) including sunitinib, sorafenib, and pazopanib, two target the mammalian target of rapamycin (temsirolimus and everolimus), and one is a humanized monoclonal antibody (bevacizumab in combination with interferon- $\alpha$ ). The current review focuses on the newest TKI available to treat patients with metastatic RCC, pazopanib. The development of this agent both preclinically and clinically is reviewed. The efficacy and safety data from the pivotal clinical trials are discussed, and the potential role of pazopanib in the treatment of patients with metastatic RCC in comparison to other treatment alternatives is critically appraised. This agent has a favorable overall risk benefit, and the available data demonstrate efficacy in patients with metastatic RCC who are either treatment-naïve or cytokine refractory. It therefore represents another alternative for treatment of metastatic RCC patients.
\end{abstract}

Keywords: renal cell carcinoma, metastatic, pazopanib

\section{Introduction: management of metastatic renal cell carcinoma (RCC)}

The management of RCC has undergone significant changes during the past 10 years. Surgical innovation has reduced morbidity and currently surgery utilizing less invasive approaches which preserve efficacy are emphasized. The therapy for metastatic RCC has seen the greatest change, reflecting an enhanced understanding of this tumor's underlying biology, which was then translated into the development of a new treatment paradigm.

RCC accounts for $2 \%$ to $3 \%$ of all malignant tumors, and is the sixth leading cause of death in the US. An estimated 58,000 new renal tumors were diagnosed in 2010, with approximately 13,000 deaths reported. ${ }^{1}$ It is most common in the seventh decade of life, and a male to female predominance of 1.6 to 1.0 is present. Worldwide, the incidence of RCC is over 200,000 new cases annually, with over 100,000 deaths 
per year. ${ }^{2}$ Active and passive cigarette smoking is the major recognized risk factor for $\mathrm{RCC}$, with a relative risk (RR) of approximately two- to three-fold. ${ }^{3}$

Current therapeutic approaches for management of patients with metastatic RCC utilize knowledge of histology, molecular abnormalities, clinical prognostic factors, knowledge of the natural history of RCC, and the treatment efficacy and toxicity of available agents (Figure 1). Histology plays a significant role in treatment outcome and selection. Epithelial RCC includes various histologic subtypes, which have unique morphologic and genetic characteristics. Clear cell RCC is the most common epithelial subtype, accounting for $75 \%-85 \%$ of these tumors, and arises from the proximal convoluted tubule. Importantly, over $80 \%$ of sporadic clear cell RCC are associated with defects in the von Hippel-Lindau (VHL) gene. ${ }^{4}$ Additional gene mutations and deletions have been recently identified, ${ }^{5}$ however their importance and relevance are as yet unclear. The remaining subtypes of epithelial RCC are collectively referred to as non-clear cell carcinomas, with papillary RCC being the most common type (10\%-15\%). Understanding histologic subtypes and associated molecular alterations has provided the framework within which diseasespecific therapy has developed.
Approximately 2\%-3\% of cases of RCC are familial and several autosomal dominant syndromes have been described, each with a distinct genetic basis and phenotype. ${ }^{6}$ Most common is the VHL syndrome (1/36,000 births), characterized by the development of vascular tumors including clear cell RCC, hemangioblastomas of the central nervous system, and pheochromocytomas. ${ }^{7}$ The tumor suppressor gene responsible for this syndrome is located on chromosome 3 (3p25-26). ${ }^{8}$ Patients with the VHL syndrome inherit a defect on one allele of the VHL gene, and acquire a defect in the remaining allele. The majority of patients with sporadic (noninherited) clear cell RCC acquire defects of both alleles of the VHL gene with resulting dysfunction of the VHL protein. In sporadic clear cell RCC, both the maternal and paternal VHL alleles are inactivated by acquired mutations. The VHL protein functions as a tumor suppressor, and is responsible for ubiquination and proteasome degradation of hypoxia-inducible factor (HIF), a regulator of the hypoxic response. ${ }^{9}$ Under hypoxia, or when VHL protein is nonfunctional, it does not bind and inactivate HIF- $\alpha$, resulting in its accumulation. This in turn activates transcription of a variety of hypoxia-inducible genes, including vascular endothelial growth factor (VEGF), platelet-derived growth factor- $\beta$

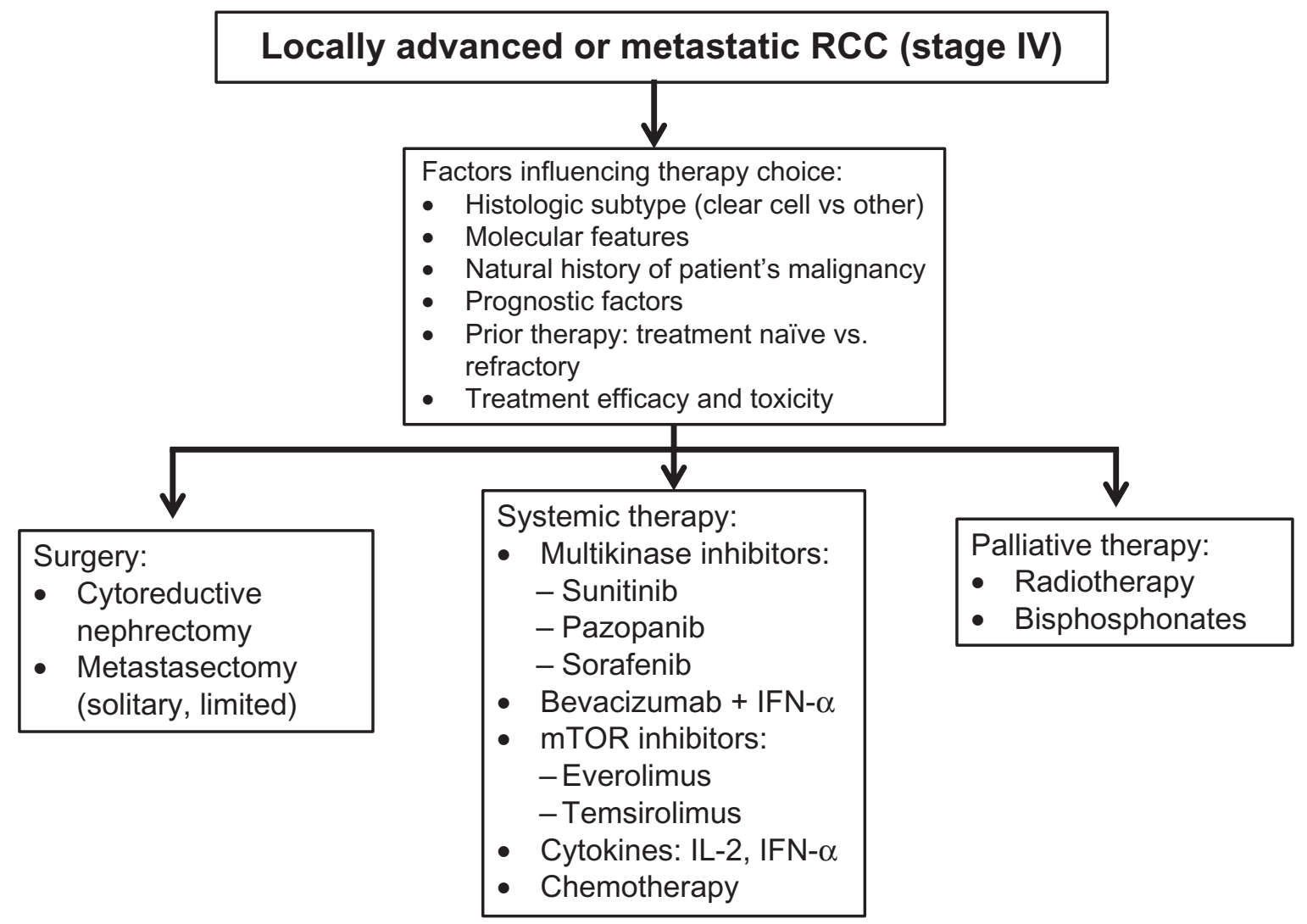

Figure I Flow diagram illustrating decision factors and therapeutic alternatives in patients with locally advanced and metastatic renal cell carcinoma. 
(PDGF- $\beta$ ), transforming growth factor- $\alpha$, and erythropoietin. Clear cell cancers are highly vascular, secondary in part to stimulation of tumor associated angiogenesis. VHL protein plays a pivotal role in the control of neoangiogenesis, and loss of VHL gene function results in enhanced secretion of VEGF, PDGF, and creation of the vascular phenotype characteristic of clear cell RCC.

Retrospective analysis of untreated metastatic RCC patients has identified clinical characteristics associated with differences in prognosis. An initial model was developed at Memorial Sloan-Kettering Cancer Center (MSKCC), and validated at the Cleveland Clinic. ${ }^{10,11}$ These risk criteria have now been utilized in a series of Phase III clinical trials. The five factors include low Karnofsky performance status $(<80 \%)$, low serum hemoglobin, high corrected calcium, elevated lactate dehydrogenase, and short disease-free interval ( $<1$ year). Prognostic groups were defined as favorable (no factors), intermediate ( $\leq 2$ factors), and poor ( $\geq 3$ factors), with median overall survival (OS) of 28.0, 13.6, and 4.6 months, respectively. ${ }^{10}$ Recently, these criteria have been reexamined, and alternate models proposed. ${ }^{12}$

Finally, an understanding of the natural history of RCC is critical in understanding the clinical course of metastatic RCC patients, and planning treatment. Issues such as management of synchronous metastatic disease, indolent disease patterns, long disease-free intervals in selected patients, patterns of metastatic disease, and the frequency of disease recurrence in sites such as the central nervous system and bone are important considerations. A complete discussion of these is beyond the scope of this review, and the reader is referred to recent reviews. ${ }^{13}$ In this context, a new treatment paradigm utilizing molecularly targeted agents has been developed for patients with metastatic clear cell RCC.

Treatment options for patients with metastatic RCC have changed dramatically over the past 6 years, and a new paradigm has evolved. Interferon- $\alpha$ (INF- $\alpha$ ) and interleukin-2 (IL-2) were the previous mainstays of therapy, ${ }^{14}$ but since December 2005, six new agents have been approved in the US for the treatment of advanced RCC. Three are multi-targeted tyrosine kinase inhibitors (TKIs) including sunitinib, ${ }^{15}$ sorafenib, ${ }^{16}$ and pazopanib, ${ }^{17}$ two target the mammalian target of rapamycin (temsirolimus ${ }^{18}$ and everolimus ${ }^{19}$ ), and one is a humanized monoclonal antibody (bevacizumab in combination with INF- $\alpha$ ) which targets VEGF. ${ }^{20}$ Sunitinib has emerged as the standard-of-care for treatment-naïve RCC patients, with the recent approvals of the bevacizumab and IFN- $\alpha$ combination and pazopanib providing additional options for frontline therapy.

\section{Pazopanib: mode of action, clinical pharmacology Preclinical}

Pazopanib (GW786034; Votrient $^{\mathrm{TM}}$, GlaxoSmithKline, NC) is an indazolylpyrimidine 5-[[4- $\{(2,3$-dimethyl-2H-indazol6-yl)methylamino \}-2-pyrimidinyl]amino]-2-methylbenzenesulfonamide that is orally bioavailable (Figure 2). It was discovered during the screening of samples which included agents which inhibited the activities of VEGF receptor (VEGFR). ${ }^{22}$ A monohydrochloride pyrimidine containing compound, pazopanib, which demonstrated both a favorable pharmokinetic profile and in vivo antitumor efficacy, was then selected for further development. When pazopanib was administered orally, optimal antitumor in vivo activity was noted. Since pazopanib demonstrated potency and selective inhibition of VEGFR, it was selected for further preclinical and clinical development..$^{22,23}$

Kumar et $\mathrm{al}^{24}$ investigated the in vitro and in vivo pharmacodynamics of pazopanib. The inhibition of VEGF-induced phosphorylation of a wide variety of kinases in vitro was characterized. Kinases targeted for study included VEGFR1, VEGFR2 (from human, dog, mouse, and rat), VEGFR3, and a number of non-VEGFR kinases. Pazopanib inhibited the VEGFR kinase family, including VEGFR1, VEGFR2, and VEGFR3, and had similar activities against PDGFR $\alpha$, PDGFR $\beta$, and c-Kit (Table 1). Modest activity against fibroblast growth factor receptor 1, fibroblast growth factor receptor 3 , and the $\mathrm{c}-\mathrm{fms}$ receptor was also noted. It appeared from these data that pazopanib demonstrated modest selectivity in vitro.

Preclinical evaluation to assess the optimal pazopanib concentrations required for in vivo antitumor/antiangiogenic activity was also conducted. ${ }^{24}$ In vivo inhibition of VEGFR2 phosphorylation in immunocomprised mice was assessed. Various transplantable tumor cell suspensions (HT29, A375P, PC3, Caki-2) were injected subcutaneously. In view of the poor solubility of pazopanib, sufficient parenteral drug levels were not achieved and a related compound, GW771806, with a kinase inhibitory spectrum similar to pazopanib was substituted. In vivo, $\mathrm{C}_{\max }$, and drug exposure (area under curve [AUC]) did not appear to correlate with activity.

Pazopanib was further evaluated using oral administration. Dose-dependent growth inhibition of all tumor xenografts was reported, however, Caki-2, a RCC cell line, was the most sensitive to pazopanib (77\% inhibition at $10 \mathrm{mg} / \mathrm{kg}$ dose, and complete inhibition at $100 \mathrm{mg} / \mathrm{kg}$ dose).

The effects of pazopanib on VEGF-induced VEGFR2 phosphorylation were then evaluated in vivo utilizing 
<smiles>Cc1ccc(Nc2nccc(N(C)c3ccc4c(C)n(C)nc4c3)n2)cc1S(N)(=O)=O</smiles>

Molecular formula: $\mathrm{C} 21 \mathrm{H} 23 \mathrm{~N} 7 \mathrm{O} 2 \mathrm{~S} \cdot \mathrm{HCl}$

Chemical name: 5-[[4-\{(2,3-dimethyl-2H-indazol-6-yl)methylamino $\}-$ 2pyrimidinyl]amino]-2-methylbenzenesulfonamide monohydrochloride Molecular weight: 473.99

Figure 2 Molecular structure and chemical name of pazopanib. ${ }^{21}$

endothelial cells from mouse lungs and tumors. In the tumor xenograft studies, VEGFR2 phosphorylation of endothelial cells was not seen, perhaps reflecting low vessel density. In contrast, a single per os dose of $30 \mathrm{mg} / \mathrm{kg}$ of pazopanib inhibited lung endothelial VEGFR2 phosphorylation for over 8 hours. This dose corresponded to a plasma concentration $>40 \mu \mathrm{mol} / \mathrm{L}$. Below this, inhibition of VEGFR2 phosphorylation was minimal. These preclinical studies suggested

Table I In vitro activity of pazopanib in purified human kinase and cell-based receptor assays ${ }^{24}$

\begin{tabular}{|c|c|c|c|}
\hline \multirow[b]{2}{*}{$\begin{array}{l}\text { Kinase or } \\
\text { receptor }\end{array}$} & \multirow{2}{*}{$\begin{array}{l}\text { Activity against } \\
\text { purified kinases }^{\text {a }}\end{array}$} & \multicolumn{2}{|c|}{$\begin{array}{l}\text { Cellular IC } \text { I }_{50} \text { inhibition of } \\
\text { ligand-induced receptor } \\
\text { autophosphorylation }^{\text {b }}\end{array}$} \\
\hline & & Cells & $\begin{array}{l}\text { Pazopanib } \\
I_{50}(n M)\end{array}$ \\
\hline VEGFRI & 15 & ND & ND \\
\hline VEGFR2 & 8 & HUVEC & 8 \\
\hline VEGFR3 & 10 & ND & ND \\
\hline PDGFR $\alpha$ & 30 & HFF & 3 \\
\hline PDGFR $\beta$ & 14 & ND & ND \\
\hline$c-K i t$ & 2.4 & $\mathrm{NCl}-\mathrm{H} 526$ & 2.6 \\
\hline Flt-3 & 230 & RS4;II & $\geq 1,000$ \\
\hline
\end{tabular}

Notes: ${ }^{2}$ Tyrosine kinase inhibitors tested in a panel of kinases at 03 and $10.0 \mu \mathrm{M}$ utilizing Profile Express (Millipore, Billerica, MA); ${ }^{b}$ cellular inhibitory activity of tyrosine kinase inhibitors against wild-type receptors on cells noted employing autophosphorylation inhibition.

Abbreviations: IC, inhibitory concentrations; VEGFR, vascular endothelial growth factor receptor; PDGFR, platelet derived growth factor receptor; HUVEC, human umbilical vein endothelial cells; ND, not done. pazopanib concentrations of $\geq 40 \mu \mathrm{mol} / \mathrm{L}$ would probably be required for optimal VEGFR2 inhibition, whereas the in vitro data suggested an $\mathrm{IC}_{50}$ of $0.02 \mu \mathrm{mol} / \mathrm{L}$. The reasons for this difference may be related to the significant protein binding of pazopanib.

\section{Clinical}

The pharmacokinetics of pazopanib in human subjects were investigated in a Phase I clinical trial ${ }^{25}$ in which 63 patients with refractory solid tumors received escalating doses of pazopanib (50 mg three times weekly, 50-2000 mg daily, and 300-400 mg twice daily). Plasma pazopanib was detected at all dose levels, however, its oral bioavailability and solubility are low, and therefore, absorption at doses above $800 \mathrm{mg}$ once daily was limited. Geometric mean pazopanib $t_{1 / 2}$ values ranged from 18.1 hours to 52.3 hours. In patients receiving $800 \mathrm{mg}$ once daily the mean $\mathrm{t}_{1 / 2}$ was 30.9 hours. Mean $\mathrm{C}_{\max }$ and $\mathrm{AUC}_{0-24}$ on day 1 increased with increasing pazopanib dose levels. The highest values were seen in patients receiving $2000 \mathrm{mg}$ daily. No evidence of drug accumulation was observed, and the steady-state exposure plateaued at $800 \mathrm{mg}$ daily. These data suggested increasing pazopanib doses above $800 \mathrm{mg}$ would not produce increased plasma drug levels. This schedule and dose were subsequently selected for Phase II and Phase III clinical trials. 
Pazopanib absorption increases when administered with food, therefore, it is administered in the fasting state. ${ }^{26}$ It is highly protein bound $(>98.8 \%)^{24}$ and is metabolized by cytochrome P450 (CYP) 3A4, and to a lesser degree by CYP1A2 and CYP2C8. ${ }^{26}$ Potential interactions with CYP3A4 inhibitors or inducers are possible, but none have been reported. Pazopanib is excreted primarily via the fecal route. Studies estimate less than $4 \%$ is excreted in the urine, and therefore impaired renal function is not likely to alter systemic exposure. ${ }^{26}$ Pazopanib metabolites are produced at low levels, and probably do not contribute to drug activity. Finally, age, race, and gender are reported to have minimal effects on the pharmacokinetics of pazopanib, ${ }^{26}$ however, formal studies in Asians have not been reported.

\section{Pazopanib: clinical trials}

A series of clinical trials investigating the toxicity and efficacy of pazopanib have been reported. These include a Phase I trial in solid tumor patients, two large randomized trials in patients with advanced RCC, and a series of Phase I and II studies to assess pazopanib in various RCC patient subsets, or in combination with other targeted agents.

\section{Phase I trial}

The Phase I pazopanib clinical trial demonstrated that it was well tolerated and had antitumor activity. ${ }^{25}$ Mild-tomoderate hypertension, diarrhea, hair depigmentation, and nausea were observed. Hypertension was the most frequent grade 3 adverse event. In 12 patients with metastatic RCC, a partial response was seen in two, stable disease in four, and progressive disease in four. These results demonstrated pazopanib was tolerated over a range of doses. The $800 \mathrm{mg}$ once daily dose was recommended for future studies.

\section{Phase II randomized discontinuation trial (RDT)}

Based on this initial information, a Phase II $\mathrm{RDT}^{27}$ was designed. ${ }^{28}$ Metastatic RCC patients received $800 \mathrm{mg}$ pazopanib orally on a daily schedule. Eligibility required metastatic or locally recurrent predominant clear cell RCC, treatment-naïve or cytokine/bevacizumab refractory patients, and measurable disease by Response Evaluation Criteria in Solid Tumors (RECIST). An RDT design was employed initially, with all subjects receiving study drug. Patients with stable disease at 12 weeks were randomized to either continue pazopanib or a placebo. After approximately 60 patients had been entered, an interim analysis was performed. The overall response rate (ORR) in this group was 38\%, and the Data Monitoring Committee recommended the trial be modified. The RTD approach was discontinued, and all patients received open-label drug until disease progression. The original sample size estimate as defined in the RTD study was utilized, namely, the progressive disease rate at 16 weeks post-randomization.

There were 225 patients entered into this trial, including the 55 patients from the RDT portion. The ORR was 35\% (95\% confidence interval [CI]: 28\%-41\%), when assessed by an independent review committee (IRC), and 34\% (95\% CI: $28 \%-40 \%$ ) by investigator assessment. The ORR was similar in the treatment-naïve (34\%, 95\% CI: 26\%-41\%) and refractory patients $(37 \%, 95 \% \mathrm{CI}: 26 \%-49 \%)$. The median response duration was 68 weeks, and median progression free survival (PFS) 52 weeks (95\% CI: 44-60 weeks).

Pazopanib was well tolerated, and the most common adverse events reported included diarrhea, fatigue, and hair depigmentation. Elevations of hepatic enzymes were seen, with increases of alanine aminotransferase (ALT) (54\%) and/or aspartate aminotransferase (AST) (53\%). Grade 3 or 4 elevations occurred in $7 \%$ and $10 \%$ of patients, respectively.

These Phase II results demonstrated significant clinical activity in patients with metastatic clear cell RCC. In view of previous reports documenting tumor regression and improved PFS in metastatic RCC patients receiving sunitinib, ${ }^{15}$ sorafenib, ${ }^{16}$ or bevacizumab, ${ }^{20}$ this type of clinical result should have been expected. The RDT design was therefore not optimal, since it required discontinuation of an active agent in the setting of stable disease and/or an evolving clinical response.

\section{Phase III randomized trial}

Demonstration of pazopanib's clinical benefit in metastatic RCC required a randomized, double-blind, placebo-controlled Phase III trial. ${ }^{17}$ This pivotal study was designed and conducted at a time when standard therapy for metastatic RCC was in transition. This transition occurred at different times in different areas of the world. The study was placebocontrolled in order to definitively establish the activity of pazopanib, and provided placebo subjects the opportunity to crossover to pazopanib upon progression. When sunitinib or sorafenib were made available in various regions, enrolment ceased, unless access to the new agent was not possible. Untreated or cytokine refractory/intolerant patients with metastatic clear cell RCC were eligible. PFS based on IRC review was the primary endpoint. Secondary endpoints included ORR, OS, and toxicity. 435 patients (233 untreated, 202 previous cytokine therapy) were randomized (2:1 ratio) 
to either pazopanib $800 \mathrm{mg}$ once daily $(\mathrm{n}=290)$ or a placebo $(n=145)$. At the time of progression patients on the placebo arm were unblinded, and were then eligible for crossover to open-label pazopanib (extension trial, VEG107769). Blinding was discontinued for all subjects after the final PFS analysis, and placebo-treated subjects without progressive disease had the option to receive pazopanib (VEG107769). The trial design permitted detection of an $80 \%$ improvement in PFS and 50\% improvement in OS.

The study results have been updated on several occasions. ${ }^{17,29,30}$ The two arms were well balanced, and $95 \%$ of patients were either favorable or intermediate risk (MSKCC criteria). ${ }^{10}$ All patients had clear cell $(90 \%)$ or predominantly clear cell histology (10\%). Prior nephrectomy had been performed in approximately $90 \%$ of patients. The intent-totreat population included 233 untreated and 202 cytokine refractory patients. The study demonstrated improvement in median PFS for patients receiving pazopanib compared with the placebo group (9.2 months vs 4.2 months, hazard ratio [HR] for progression: $0.46, P<0.0000001)$. This difference was more pronounced in treatment-naïve patients (11.1 months vs 2.8 months, HR: $0.40, P<0.0000001)$ than in the cytokine refractory group (7.4 months vs 4.2 months, HR: $0.54, P<0.001)$. A prespecified analysis of trial subgroups demonstrated that improvement of PFS was independent of age, performance status, gender, and MSKCC risk group. The data for the various MSKCC risk groups are not yet available.

ORR was higher in all patients receiving pazopanib compared with the control group (30\% vs 3\%). In treatment-naïve subjects, the ORR was $32 \%$ vs $4 \%$ for the placebo group. The median response duration was 59 weeks.

Selected efficacy data reported in various first-line Phase II/III trials of VEGF/VEGFR inhibitors in metastatic RCC patients (excluding the temsirolimus trial) are summarized in Table 2 (PFS), and Table 3 (OS). The ORR in treatment-naïve patients varies between $5.2 \%$ and $47 \%$ depending upon the trial, agent utilized, and type of analysis (independent vs investigator). The most active agent appears to be sunitinib, with an ORR of $37 \%$ (47\% investigator assessment). ${ }^{15,34}$ The ORR observed with pazopanib appears similar (32\% vs 37\%). Responses appear to be durable with all agents, with median response durations between 11.0 months and 14.0 months.

An interim survival analysis in the pazopanib Phase III trial initially reported a median OS of 21.1 months for pazopanib vs 18.7 months for the placebo patient group (HR: 0.73 , one-sided $P=0.02) .{ }^{17}$ Final OS data are available, and revealed a median OS of 22.9 months for the pazopanib vs 20.5 months in the placebo cohort (HR: $0.91,95 \% \mathrm{CI}$ : $0.71-1.16$, stratified $\log \operatorname{rank} P=0.224) .{ }^{29} \mathrm{~A}$ high rate of secondary therapy in placebo patients compared with those randomized to pazopanib was reported (66\% vs 30\%), with $54 \%$ of the placebo group ultimately receiving pazopanib. ${ }^{29}$ In an inverse probability censoring weighted analysis which adjusts for the activity of pazopanib vs placebo, pazopanib therapy was associated with a $50 \%$ reduction in the risk of death.

Direct comparisons between the various trial results are not possible in view of the different trial designs and patient populations treated. Since the trials were conducted using similar endpoints and evaluation methods, the PFS data from these studies is illustrated in Figure 3. The effect of pazopanib on PFS appears comparable to that of the other anti-angiogenic agents in either treatment-naïve or cytokine pretreated subjects.

The pazopanib data have been compared ${ }^{37}$ to the Phase III trial results with sunitinib, ${ }^{15,34}$ sorafenib, ${ }^{16,38}$ and bevacizumab plus IFN- $\alpha . .^{20,35}$ The adjusted indirect comparison methodology was utilized. Patient characteristics were reported as similar across the various trials. This approach suggested that pazopanib is superior to IFN- $\alpha$ with a PFS HR (HR: $0.50,95 \%$ CI: $0.31-0.81)$. In treatment-naïve patients, the indirect PFS

Table 2 Progression free survival in frontline metastatic renal cell cancer randomized trials

\begin{tabular}{|c|c|c|c|c|c|c|}
\hline \multirow[t]{2}{*}{$\begin{array}{l}\text { Clinical trial/ } \\
\text { Agent or regimen }\end{array}$} & \multirow{2}{*}{$\begin{array}{l}\text { Sunitinib } \\
\text { vs IFN- } \alpha^{15} \\
(n=750)\end{array}$} & \multicolumn{2}{|c|}{$\begin{array}{l}\text { Bevacizumab+ } \\
\text { IFN- } \alpha \text { vs IFN- } \alpha\end{array}$} & \multirow{2}{*}{$\begin{array}{l}\text { Pazopanib } \\
\text { vs placebo }^{17} \\
(n=233)\end{array}$} & \multirow{2}{*}{$\begin{array}{l}\text { Sorafenib } \\
\text { vs IFN- } \alpha^{32} \\
(\mathrm{n}=189)\end{array}$} & \multirow{2}{*}{$\begin{array}{l}\text { Sorafenib } \pm \text { AMG386 } \\
(3.0,10 \mathrm{mg}) \\
(\mathrm{n}=15 \mathrm{I})\end{array}$} \\
\hline & & $\begin{array}{l}\text { Avoren }^{20} \\
(n=649)\end{array}$ & $\begin{array}{l}\text { CALGB } 90206^{31} \\
(n=732)\end{array}$ & & & \\
\hline $\begin{array}{l}\text { Sunitinib, } \\
\text { bevacizumab + IFN- } \alpha \text {, } \\
\text { sorafenib, pazopanib }\end{array}$ & $11.0 \mathrm{mos}$ & $10.2 \mathrm{mos}$ & $8.5 \mathrm{mos}$ & II.I mos & $5.7 \mathrm{mos}$ & $9.0 \mathrm{mos}$ \\
\hline $\begin{array}{l}\text { INF- } \alpha \text {, placebo, } \\
\text { AMG } 386 \text { + sorafenib }\end{array}$ & $5.0 \mathrm{mos}$ & $5.4 \mathrm{mos}$ & $5.2 \mathrm{mos}$ & $2.8 \mathrm{mos}$ & $5.6 \mathrm{mos}$ & $8.5,9.0 \mathrm{mos}$ \\
\hline$P$ value & $<0.001$ & $<0.0001$ & $<0.0001$ & $<0.000$ I & 0.504 & 0.532 \\
\hline
\end{tabular}

Abbreviation: INF- $\alpha$, interferon-alpha. 
Table 3 Overall survival in randomized trials: frontline metastatic renal cell cancer patients

\begin{tabular}{llllll}
\hline $\begin{array}{l}\text { Clinical trial/ } \\
\text { Agent or regimen }\end{array}$ & Sunitinib vs IFN- $\alpha^{34}$ & AVOREN $^{35}$ & CALGB 90206 & Sorafenib vs IFN- $\alpha^{32}$ & Pazopanib vs placebo $^{29}$ \\
\hline $\begin{array}{l}\text { Sunitinib, bevacizumab+ } \\
\text { IFN- } \alpha \text {, pazopanib }\end{array}$ & $26.4 \mathrm{mos}$ & $23.3 \mathrm{mos}$ & $18.3 \mathrm{mos}$ & $\mathrm{NR}$ & $22.9 \mathrm{mos}$ \\
INF- $\alpha$, placebo & $21.8 \mathrm{mos}$ & $21.3 \mathrm{mos}$ & $17.4 \mathrm{mos}$ & $\mathrm{NR}$ & $20.5 \mathrm{mos}$ \\
$\begin{array}{l}P \text { value } \\
\text { Hazard ratio }(95 \% \mathrm{Cl})\end{array}$ & $0.05 \mathrm{I}$ & $0.129 \mathrm{I}$ & 0.069 & $\mathrm{NA}$ & 0.224 \\
\hline
\end{tabular}

Abbreviations: $\mathrm{Cl}$, confidence interval; INF- $\alpha$, interferon-alpha; mos, months.

HR suggested pazopanib was not statistically different from sunitinib (HR: 0.93, 95\% CI: 0.56-1.56) or bevacizumab plus IFN- $\alpha$ (HR: $0.79,95 \%$ CI: $0.48-1.32$ ). In cytokine refractory patients, the indirect PFS HR suggests that pazopanib is not different from sorafenib (HR: 0.98, 95\% CI: 0.61-1.58). Further information from comparative randomized trials is now required to validate such comparisons. Currently, significant improvement in PFS is a surrogate endpoint accepted as demonstrating clinical benefit of therapy in metastatic RCC patients, and appears to correlate with OS. ${ }^{39}$ The ultimate effect on survival however, remains a critical determinant of effectiveness. Comparisons of OS data were not reported by this group.

\section{Phase II pazopanib trials: refractory patients}

Recently, several groups have examined the efficacy of pazopanib in RCC patients who have progressed on other targeted agents including TKIs, bevacizumab, and mammalian target of rapamycin inbitors..$^{40,41}$ A Phase II trial in 44 patients who had progressed or were intolerant of first-line sunitinib or bevacizumab was reported by Reeves et al. ${ }^{40}$

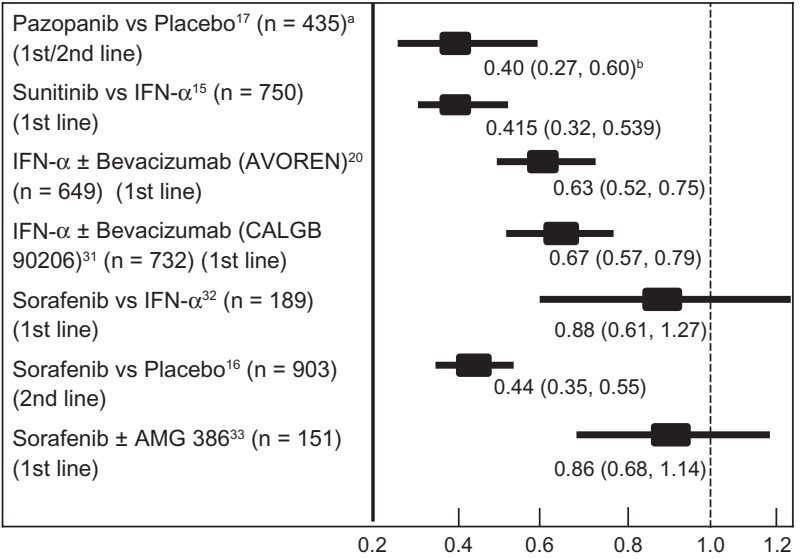

Figure 3 Comparison of progression free survival data from recent phase II and III randomized clinical trials utilizing a variety of targeted agents in treatment-naïve or cytokine refractory patients with metastatic renal cell carcinoma. Notes: a patient number; 'hazard ratio ( $95 \%$ confidence interval).
These results are summarized in Table 4 and suggest pazopanib has activity in this subset of patients. A report from MD Anderson Hospital ${ }^{41}$ retrospectively reviewed 88 consecutive refractory RCC patients who had received one or more targeted therapies which included sunitinib (78\%), sorafenib $(40 \%)$, temsirolimus $(20 \%)$, everolimus $(51 \%)$, or bevacizumab (26\%). This was a heavily pretreated group, with $26 \%$ having also received prior chemotherapy, and $16 \%$ prior cytokines. In patients failing one prior agent, an ORR of $42 \%$ was found, in contrast to $18 \%$ in patients failing more than one targeted treatment. In both reports, the toxicity of pazopanib was similar to that noted previously. Seven percent and $10 \%$ of patients discontinued pazopanib secondary to adverse drug events, respectively. These two reports suggest pazopanib has clinical activity not only in the cytokine refractory patient, but also in patients failing targeted agents.

\section{Phase I pazopanib combination trials}

Several Phase I trials are in progress investigating administration of pazopanib with other targeted agents, including bevacizumab (NCT 00992121) 42 $^{2}$ and everolimus (NCT 01184326). ${ }^{43} \mathrm{~A}$ recent report ${ }^{44}$ summarized the results of a phase I dose escalation trial combining temsirolimus and pazopanib to define the combination's dose limiting toxicity (DLT). Solid tumor patients were eligible. The starting dose level included temsirolimus administered at a dose of $15 \mathrm{mg}$ intravenously weekly, and pazopanib $400 \mathrm{mg}$ per os daily.

Table 4 Phase II trial pazopanib in patients refractory to sunitinib or bevacizumab ${ }^{40}$

\begin{tabular}{llll}
\hline & All patients & $\begin{array}{l}\text { Previous } \\
\text { sunitinib }\end{array}$ & $\begin{array}{l}\text { Previous } \\
\text { bevacizumab }\end{array}$ \\
\hline Number & 44 & 32 & 12 \\
ORR & $9(20 \%)$ & $5(16 \%)$ & $4(33 \%)$ \\
DCR (CR + PR + SD) & $31(77 \%)$ & $21(66 \%)$ & $10(83 \%)$ \\
Median PFS & $9.23(95 \%$ & $12.06(95 \%$ & $8.05(95 \%$ \\
(months) & Cl: $5.42, \mathrm{NA})$ & Cl: $6.14, \mathrm{NA})$ & $\mathrm{Cl}: 2.76,11.93)$ \\
\hline
\end{tabular}

Abbreviations: $\mathrm{Cl}$, confidence interval; ORR, overall response rate; $\mathrm{DCR}$, disease control rate; NA, not available, PFS, progression free survival; CR, complete response; PR, partial response; SD, stable disease. 
DLT was encountered at dose level 1 , and a second dose level utilizing dose reductions of temsirolimus to $10 \mathrm{mg}$ intravenously weekly and pazopanib to $200 \mathrm{mg}$ daily was opened. DLT was again encountered. This trial enrolled only eight patients, but the authors suggest further development of this combination is not recommended secondary to grade 3 fatigue and electrolyte disturbances which limited therapy at lower than optimal dose levels. The possibility pazopanib will resemble sunitinib and sorafenib when combined with other targeted agents and produce unacceptable toxicity is suggested by these preliminary observations, and the results of the other combination trials are needed to fully assess this issue.

\section{Strategies to increase pazopanib efficacy}

One approach to enhance the efficacy of current RCC therapy involves development of biomarkers for patient selection. Clinical response to pazopanib therapy varies between patients, and biomarkers possibly predictive of treatment outcome have recently been identified. $\mathrm{Xu}$ and colleagues ${ }^{45}$ evaluated 27 single nucleotide polymorphisms within 13 genes in 397 patients with RCC receiving pazopanib. The association with PFS and ORR was analyzed, with a recent update of the results examining correlations with $\mathrm{OS}^{46}$ (Table 5). Polymorphisms in IL-8, HIF1A, NR112, and VEGFA showed nominally significant association $(P \leq 0.05)$ with PFS when compared with the wild-type genotypes. Similarly, polymorphisms in IL-8, fibroblast growth factor receptor 2, VEGFRA, FLT4, and NR112 in 241 patients were associated with OS. The data suggest germline variants in angiogenesis- and drug exposure-related genes may predict pazopanib efficacy in metastatic RCC patients, and may also be useful in predicting treatment failure in certain patients. Validation of these results is now required, but these approaches appear to provide an alternative strategy to enhance efficacy.
Finally, the relationship of drug exposure and efficacy of various TKIs in metastatic RCC has been suggested by several investigators. ${ }^{47}$ Suttle et $\mathrm{l}^{48}$ have investigated this relationship between pazopanib plasma concentrations at 4 and 12 weeks in patients treated in the phase II RTD pazopanib trial. A Cox regression analysis was utilized. Pharmacokinetic data were available from 205 patients. The median PFS in patients with a plasma pazopanib concentration $\geq 20.6 \mu \mathrm{g} / \mathrm{mL}(\mathrm{n}=143$ ) at week 4 was 49.4 weeks vs 20.3 weeks for those with lower values ( $\mathrm{n}=62, P=0.0041$ ). Additionally, pazopanib concentrations at week 4 above $20.6 \mu \mathrm{g} / \mathrm{mL}$ were associated with a significantly higher ORR (64/143 vs $11 / 62$ or $45 \%$ vs $18 \%, P=0.000017)$. These data suggest pazopanib concentrations $>20.6 \mu \mathrm{g} / \mathrm{mL}$ may be associated with improved efficacy. Prospective studies to optimize pazopanib exposure in non-responding patients who have levels $\leq 20.6 \mu \mathrm{g} / \mathrm{mL}$ would be of interest.

\section{Comparative Phase III pazopanib trials}

Several Phase III trials comparing pazopanib and sunitinib are in progress, and will provide important information on the comparative efficacy and tolerability of these two TKIs. VEGF pathway inhibitors produce a constellation of common side effects including fatigue, diarrhea, hypertension, and nausea. Potential differences between adverse event profiles may reflect the mechanisms of action, types of targets inhibited, potency, VEGF pathway inhibition selectivity, and pharmacokinetic differences. In the case of pazopanib, a Phase III trial directly comparing pazopanib and sunitinib is underway. This international blinded controlled trial (COMPARZ trial) randomizes untreated patients with metastatic clear cell RCC to either to pazopanib $800 \mathrm{mg}$ daily or sunitinib $50 \mathrm{mg}$ /day for 4 weeks on and 2 weeks off therapy. ${ }^{49}$ The study is adequately powered $(n=876)$ for noninferiority, and will provide information on the efficacy and, importantly, the tolerability of

Table 5 Genotypes for single nucleotide polymorphisms associated with pazopanib efficacy ${ }^{45,46}$

\begin{tabular}{|c|c|c|c|c|c|}
\hline \multicolumn{2}{|c|}{ Polymorphisms } & \multicolumn{2}{|c|}{ Progression free survival } & \multicolumn{2}{|c|}{ Overall survival } \\
\hline & & \multirow{2}{*}{$\begin{array}{l}\text { Median (weeks) } \\
48\end{array}$} & \multirow{2}{*}{$\begin{array}{l}P \text { value } \\
0.009\end{array}$} & \multirow{2}{*}{$\begin{array}{l}\text { Median (mos) } \\
29.6\end{array}$} & \multirow{2}{*}{$\begin{array}{l}P \text { value } \\
0.002\end{array}$} \\
\hline IL-8 & $\mathrm{AA}$ & & & & \\
\hline $2767 \mathrm{~A}>\mathrm{T}$ & $\mathrm{TT}$ & 27 & & 14.8 & \\
\hline HIFIA & GG & 44 & 0.03 & NA & - \\
\hline $1790 \mathrm{G}>\mathrm{A}$ & $\mathrm{TT}$ & 20 & & NA & \\
\hline VEGFA & GG & NA & - & 25.3 & 0.004 \\
\hline $1154 A>G$ & $\mathrm{AA}$ & NA & & 16.7 & \\
\hline NRII2 & $\mathrm{CC}$ & 48 & 0.07 & NA & - \\
\hline$-25385 \mathrm{C}>\mathrm{T}$ & $\mathrm{TT}$ & 58 & & NA & \\
\hline
\end{tabular}

Abbreviations: HIFIA, Hypoxia-inducible factor I, alpha subunit; IL-8, interlukin-8; NA, not available; VEGFA, vascular endothelial growth factor A. 
pazopanib compared with the most frequently used agent in metastatic RCC patients.

A second Phase III trial is underway to examine patient preferences with regard to initial therapy for metastatic RCC (PISCES trial). ${ }^{50}$ The design involves a randomized double blind, crossover trial in which 160 patients will receive either pazopanib or sunitinib at standard doses for two 10-week periods separated by a 2 week wash out phase. The trial will assess the tolerability and safety of these two TKIs and utilize patient reported outcomes to investigate differences.

\section{Pazopanib safety and tolerability}

Patients in the Phase II pazopanib RTD trial, ${ }^{28}$ tolerated therapy without difficulty. The most common adverse events reported included diarrhea, fatigue, and hair depigmentation. Laboratory abnormalities reported included elevated ALT (54\%) and AST (53\%), with $\geq$ grade 3 elevations noted in $7 \%$ and $9 \%$ of patients, respectively. In contrast, only mild hematologic toxicity ( $\leq$ grade 2 ) was encountered, with neutropenia and thrombopenia reported in $27 \%$ and $26 \%$ of patients, respectively.

This toxicity profile was confirmed in the Phase III pivotal trial comparing pazopanib to a placebo. ${ }^{17}$ In this study, pazopanib was also well tolerated. Table 6 summarizes the most common adverse events (all grades) experienced by patients in both treatment arms. These included diarrhea (52\%), hypertension (40\%), and hair color changes (38\%). Grade 3 and 4 adverse events were uncommon. Hand-foot syndrome, arterial thrombotic events, hypothyroidism, proteinuria, and stomatitis were noted in 3\%-9\% of patients. The most common laboratory abnormalities observed were grade 2 or less hepatic enzyme abnormalities and hyperglycemia. In a subsequent report, ${ }^{30}$ the frequency and severity of adverse events did not change despite a 30\% increase in cumulative pazopanib exposure.

Severe hepatic toxicity (grade 3 or worse) has been reported in $4 \%-12 \%$ of patients receiving pazopanib. ${ }^{28}$ Results of a meta-analysis investigating hepatic toxicity related to pazopanib are now available..$^{51}$ The studies analyzed included trials in which the pazopanib starting dose was $800 \mathrm{mg}$ daily. Summary incidence rates, RR, and 95\% CI were calculated using a fixed-effects or random-effects model. Eight trials involving 1155 patients with various solid tumors were included in the analysis. The incidence of ALT elevation was $41.7 \%$ (95\% CI: 33.9-49.9) with $8.2 \%$ (95\% CI: 5.9-11.3) characterized as high grade ( $\geq$ grade 3 ). A significant increase in high grade ALT elevation in RCC patients $(10.9 \%$ vs $5.7 \%, P=0.012)$ was noted. The incidence
Table 6 Phase III trial of pazopanib versus placebo in metastatic renal cell carcinoma - selected adverse events and clinical chemistry abnormalities ${ }^{17,29,30}$

\begin{tabular}{|c|c|c|c|c|}
\hline & \multicolumn{2}{|l|}{ Pazopanib } & \multicolumn{2}{|l|}{ Placebo } \\
\hline & All grades & $\geq$ grade 3 & All grades & $\geq$ grade 3 \\
\hline \multicolumn{5}{|l|}{ Adverse event } \\
\hline Any event & $92 \%$ & $41 \%$ & $74 \%$ & $20 \%$ \\
\hline Diarrhea & $52 \%$ & $4 \%$ & $9 \%$ & $<1 \%$ \\
\hline Hypertension & $40 \%$ & $4 \%$ & $10 \%$ & $1 \%$ \\
\hline Hair color changes & $38 \%$ & $<1 \%$ & $3 \%$ & 0 \\
\hline Nausea & $26 \%$ & $<1 \%$ & $9 \%$ & 0 \\
\hline Vomiting & $21 \%$ & $2 \%$ & $8 \%$ & $2 \%$ \\
\hline Fatigue & $19 \%$ & $2 \%$ & $8 \%$ & $2 \%$ \\
\hline Asthenia & $14 \%$ & $3 \%$ & $8 \%$ & 0 \\
\hline Bleeding & $13 \%$ & $2 \%$ & $5 \%$ & 0 \\
\hline Hand-foot & $6 \%$ & NS & $<1 \%$ & NS \\
\hline Headache & $10 \%$ & 0 & $5 \%$ & 0 \\
\hline \multicolumn{5}{|l|}{ Chemistry } \\
\hline Increased ALT & $53 \%$ & $12 \%$ & $22 \%$ & $1 \%$ \\
\hline Increased AST & $53 \%$ & $8 \%$ & $19 \%$ & $<1 \%$ \\
\hline Hyperglycemia & $41 \%$ & $<1 \%$ & $33 \%$ & $1 \%$ \\
\hline Increased bilirubin & $36 \%$ & $4 \%$ & $10 \%$ & $2 \%$ \\
\hline Hypophosphatemia & $34 \%$ & $4 \%$ & $11 \%$ & 0 \\
\hline Hypocalcemia & $33 \%$ & $2 \%$ & $26 \%$ & $1 \%$ \\
\hline Hypoglycemia & $17 \%$ & $<1 \%$ & $3 \%$ & 0 \\
\hline Neutropenia & $34 \%$ & $2 \%$ & $2 \%$ & 0 \\
\hline Thrombopenia & $32 \%$ & $1 \%$ & $5 \%$ & $<1 \%$ \\
\hline Proteinuria & $9 \%$ & NS & 0 & NS \\
\hline
\end{tabular}

Abbreviations: ALT, alanine aminotransferase; AST, aspartate aminotransferase; NS, not stated.

of AST elevation was 39.3\% (95\% CI: 30.2-49.2) with $6.4 \%$ (95\% CI: 4.6-8.8) being high grade. In this case, no differences between RCC and non-RCC patients $(7.4 \%$ vs $4.8 \%, P=0.22)$ were found. When compared to controls, an increased risk of high grade ALT elevation (RR: 7.95, 95\% CI: $2.22-28.55, P=0.001)$ and high grade AST elevation (RR: $9.01,95 \%$ CI: $1.71-47.50, P=0.01$ ) were noted. The authors conclude pazopanib administration may be associated with a risk of $\geq$ grade 3 hepatotoxicity, and the frequency may be dependent upon tumor type.

The most common adverse events associated with pazopanib, sunitinib, and bevacizumab plus IFN $\alpha$ are summarized in Table 7. Grade 3 hepatic toxicity may be more frequent with pazopanib than with other TKIs such as sunitinib. In contrast, neutropenia and thrombocytopenia appear less frequent. Such comparisons of toxicity must be investigated prospectively, however, the adverse event profiles of these three treatments have been indirectly compared. ${ }^{37}$ Adverse events were common with all agents $(92 \%-99 \%)$. The rates of serious adverse events were also similar among these treatments (27\%-34\%). The frequency of $\geq$ grade 3 adverse events was lower with pazopanib (44\%, 95\% CI: 40\%-48\%) 
Table 7 Selected adverse events (all grades and $\geq$ grade 3): sunitinib, bevacizumab + IFN- $\alpha$, and pazopanib pivotal trials

\begin{tabular}{|c|c|c|c|c|c|c|}
\hline \multirow{3}{*}{$\begin{array}{l}\text { Treatment setting/ } \\
\text { Adverse event }\end{array}$} & \multicolumn{2}{|l|}{ First-line } & \multicolumn{2}{|l|}{ First-line } & \multicolumn{2}{|c|}{ First/second line } \\
\hline & \multicolumn{2}{|l|}{ Sunitinib ${ }^{15,34}$} & \multicolumn{2}{|c|}{ Bevacizumab + IFN- $\alpha^{20}$} & \multicolumn{2}{|l|}{ Pazopanib ${ }^{17,29,30}$} \\
\hline & All grades (\%) & $\geq \operatorname{grade} 3(\%)$ & All grades (\%) & $\geq \operatorname{grade} 3(\%)$ & All grades (\%) & $\geq$ grade $3(\%)$ \\
\hline Fatigue & 54 & II & 33 & 12 & 20 & 2 \\
\hline Asthenia & 20 & 7 & 32 & 10 & 14 & 3 \\
\hline Diarrhea & 61 & 9 & 20 & 2 & 52 & 4 \\
\hline Hemorrhage & $18^{\mathrm{a}}$ & 1 & 33 & 3 & $14^{b}$ & I \\
\hline Hand-foot syndrome & 29 & 9 & - & - & 6 & $<1$ \\
\hline Hypertension & 30 & 12 & 26 & 3 & 40 & 4 \\
\hline Decline LVEF & 13 & 3 & NS & NS & $<1$ & $<1$ \\
\hline Neutropenia & 77 & 18 & 7 & 4 & 36 & I \\
\hline Thrombocytopenia & 68 & 9 & 6 & 2 & 34 & I \\
\hline Increased ALT & 51 & 3 & NS & NS & 53 & 13 \\
\hline Increased AST & 56 & 2 & NS & NS & 53 & 8 \\
\hline Increased total bilirubin & 20 & 1 & NS & NS & 36 & 4 \\
\hline $\begin{array}{l}\text { Discontinuations due to } \\
\text { adverse events }\end{array}$ & 19 & & $19 c$ & & 14 & \\
\hline
\end{tabular}

Notes: ${ }^{a}$ Epistaxsis; ball causes; 'bevacizumab discontinuation rate, rate for either agent $28 \%$.

Abbreviations: ALT, alanine aminotransferase; AST, aspartate aminotransferase; INF- $\alpha$, interferon-alpha; LVEF, left ventricular ejection fraction; NS, not stated.

compared to sunitinib (67\%, 95\% CI: $62 \%-71 \%)$ or bevacizumab plus IFN- $\alpha(60 \%, 95 \%$ CI: $55 \%-66 \%)$. This type of indirect comparison method suggests there may be differences between these agents, even including class effects such as hypertension. Safety comparisons must be interpreted based on the length of exposure to drug as well as other trial variables.

The health-related quality of life (HRQOL) data from the Phase III pazopanib vs placebo trial are also of interest when considering patient tolerability. ${ }^{52}$ HRQOL outcome was assessed using European Organization for Research and Treatment of Cancer Quality of Life Questionnaire (QLQ-C30) and EQ-5D index and visual analog scale. The time to $\geq 20 \%$ decline from baseline HRQOL was estimated for all patients, by prior therapy, and stratified by response (RECIST). The authors noted placebo treated patients were more likely to experience $\geq 20 \%$ HRQOL decline (QLQ-C30) (HR: $0.77,95 \%$ CI: $0.57-1.03, P=0.0817$ ). Patients with RECIST responses experienced significantly less HRQOL deterioration compared to progressive disease patients. These results supporting the tolerability profile of pazopanib and suggest patients who had tumor response also experienced better HRQOL compared to those without response.

\section{Conclusion: role of pazopanib in RCC therapy}

In the Phase III randomized double-blind placebo-controlled trial, pazopanib treatment produced a highly significant PFS improvement for either treatment-naïve or cytokine pretreated patients. The efficacy and safety results from this study were similar to those from the Phase II nonrandomized open label RTD trial in a similar population. Certain adverse reactions are common to the anti-VEGF agent class, however, their incidence and severity varies widely. The potential difference in the safety profiles of these agents provides treatment options for patients with advanced RCC. Pazopanib represents a treatment option with comparable efficacy, and potential important differences in tolerability vs the current standard of care. As such, it appears to represent a valuable addition to the treatment of advanced RCC. The following observations on efficacy and toxicity are relevant when considering the role of pazopanib in patients with metastatic clear cell RCC:

\section{Efficacy of pazopanib}

- A large and very significant improvement in PFS was demonstrated with pazopanib compared to a placebo in patients with advanced metastatic RCC. The concordance of the IRC and the investigator assessments demonstrate the robust nature of the findings.

- Subgroup analyses demonstrate PFS improvement was consistent across multiple clinically relevant subgroups. Importantly, these improvements were seen in prespecified groups, including both treatment-naïve and cytokine refractory patients.

- The median PFS reported in the Phase II RTD study (10.4 months) was similar to that reported in the pivotal study (all patients: 9.2 months, 
treatment-naïve: 11.1 months), and resembles those of the current standard metastatic RCC therapy sunitinib (11 months in first-line).

- The survival data suggest a favorable trend associated with pazopanib treatment, in spite of significant crossover by subjects in the placebo arm.

- The median OS of placebo patients in the pivotal study was substantially longer than reported for a historical group of metastatic RCC patients receiving cytokines. ${ }^{53}$ This may reflect the confounding effects of secondary therapy.

- The Phase II results in TKI refractory patients with pazopanib resemble those reported with other TKIs, and are consistent with a lack of cross resistance.

\section{Safety of pazopanib}

- The most common side effects of pazopanib include diarrhea, hypertension, hair color changes, nausea, fatigue, anorexia, and vomiting. Most adverse events are grade 1 or 2 , and do not require discontinuation of therapy.

- The most common serious adverse events associated with pazopanib include diarrhea, dyspnea, pleural effusion, abdominal pain, and vomiting. More serious liver function abnormalities, arterial/thrombotic events, and hemorrhagic events have also been reported.

- The most common laboratory abnormalities produced include grade 1 or 2 ALT, AST, and bilirubin elevations, hyperglycemia, and electrolyte abnormalities. The most common serious laboratory abnormalities ( $\geq$ grade 3 ) were hepatic enzyme elevations. Cytopenias occur in pazopanib treated patients, but $\geq$ grade 3 hematologic toxicity is seldom seen.

- Grade 3 or greater elevations of hepatic enzymes occur in from $8 \%$ to $13 \%$ of patients treated with pazopanib. The time course of this development is well characterized, and recommendations for monitoring liver functions are available. Importantly, these liver enzyme elevations will generally normalize with adequate follow-up. In patients who continue to receive pazopanib despite transaminase elevations, adaptation has been noted.

- Fatal liver toxicity related to pazopanib is rare $(0.05 \%$ $0.1 \%$ ), and has also been reported with other TKIs such as sunitinib and sorafenib.

- Adverse events previously described with other TKIs, such as cardiac/cerebral ischemia, hemorrhage, and bowel perforation, are also observed with pazopanib. However, no evidence of left ventricular dysfunction has been reported secondary to pazopanib administration.

- Patients receiving pazopanib may exhibit differences in tolerability when compared to individuals treated with the other approved anti-VEGF TKIs. This includes a possible lower incidence of mucositis, hand-foot syndrome, fatigue, and hematologic toxicity (Table 6).

In summary, the overall risk benefit of pazopanib appears favorable. The available data demonstrate pazopanib has efficacy in patients with metastatic RCC who are either treatment-naïve or cytokine refractory. The significant improvement of PFS compared to a placebo noted in the pivotal Phase III trial is an acceptable surrogate of clinical benefit. The final analysis of OS failed to demonstrate significant improvement, however, the influence of crossover and the confounding effects of secondary therapy may be responsible factors. The final median OS for pazopanib patients in the combined population of treatment-naive and cytokine refractory individuals was 22.4 months, for the placebo subjects was 20.1 months. The OS of this latter group is different from historical data for metastatic RCC patients who have received either a placebo or cytokine therapy. This may be a reflection of the crossover study design.

These benefits should be examined in the context of possible pazopanib associated toxicity. Pazopanib's safety profile is well documented, and the majority of adverse events are grade 1 or 2 . The frequency of grade 3 and 4 events is generally low. The majority of associated adverse events are easily managed. It is important to note that the adverse events reported with pazopanib have also been reported with the other agents approved for metastatic RCC. The incidence and severity of various adverse events varies between agents, with these differences potentially impacting drug utilization. The relatively low incidence of severe myelosuppression, hand-foot syndrome, stomatitis, and fatigue compared with the safety profile of other agents of this class such as sunitinib in metastatic RCC position pazopanib as a potential therapeutic option. The COMPARZ clinical trial which compares the safety and efficacy of pazopanib and sunitinib will provide the comparative data required to determine whether pazopanib has similar efficacy and an improved toxicity profile. Generally efficacy guides therapeutic decisions when toxicity is equivalent.

\section{Disclosure}

Consultant: GlaxoSmithKline, Pfizer, Genentech, Novartis, Argos, Agenus. Speaking: Pfizer, Genentech, Novartis. 


\section{References}

1. Jemal A, Siegel R, Xu J, Ward E. Cancer statistics, 2010. CA Cancer J Clin. 2010;60(5):277-300.

2. Ferlay J, Shin HR, Bray F, Forman D, Mathers C, Parkin DM; International Agency for Research on Cancer. GLOBOCAN 2008. Cancer incidence and mortality worldwide: CancerBase no.10. 2008. Available from: http://globocan.iarc.fr. Accessed June 21, 2011.

3. Tsivian M, Moreira DM, Caso JR, Mouraviev V, Polascik TJ. Cigarette smoking is associated with advanced renal cell carcinoma. J Clin Oncol. 2011;29(15):2027-2031.

4. Young AC, Craven RA, Cohen D, et al. Analysis of VHL gene alterations and their relationship to clinical parameters in sporadic conventional renal cell carcinoma. Clin Cancer Res. 2009;15(24):7582-7592.

5. Varela I, Tarpey P, Raine K, et al. Exome sequencing identifies frequent mutation of the SWI/SNF complex gene $P B R M 1$ in renal carcinoma. Nature. 2011;469(7331):539-542.

6. George DJ, Kaelin WG Jr. The von Hippel-Lindau protein, vascular endothelial growth factor, and kidney cancer. $N$ Engl J Med. 2003;349(5):419-421.

7. Butman JA, Linehan WM, Lonser RR. Neurologic manifestations of von Hippel-Lindau disease. JAMA. 2008;300(11):1334-1342.

8. Latif F, Tory K, Gnarra J, et al. Identification of the von Hippel-Lindau disease tumor suppressor gene. Science. 1993;260(5112):1317-1320.

9. Kaelin WG Jr. The von Hippel-Lindau tumor suppressor protein and clear cell renal carcinoma. Clin Cancer Res. 2007;13(2 Pt 2): 680s-684s.

10. Motzer RJ, Bacik J, Murphy BA, Russo P, Mazumdar M. Interferon-alfa as a comparative treatment for clinical trials of new therapies against advanced renal cell carcinoma. J Clin Oncol. 2002;20(1):289-296.

11. Mekhail TM, Abou-Jawde RM, Boumerhi G, et al. Validation and extension of the memorial Sloan-Kettering prognostic factors model for survival in patients with previously untreated metastatic renal cell carcinoma. J Clin Oncol. 2005;23(4):832-841.

12. Heng DY, Xie W, Regan MM, et al. Prognostic factors for overall survival in patients with metastatic renal cell carcinoma treated with vascular endothelial growth factor-targeted agents: results from a large, multicenter study. J Clin Oncol. 2009;27(34):5794-5799.

13. Rini BI, Campbell SC, Escudier B. Renal cell carcinoma. Lancet. 2009;373(9669):1119-1132.

14. Atkins MB, Regan M, McDermott D. Update on the role of interleukin 2 and other cytokines in the treatment of patients with stage IV renal carcinoma. Clin Cancer Res. 2004;10(18 Pt 2):6342S-6346S.

15. Motzer RJ, Hutson TE, Tomczak P, et al. Sunitinib versus interferon alfa in metastatic renal-cell carcinoma. $N$ Engl J Med. 2007;356(2):115-124.

16. Escudier B, Eisen T, Stadler WM, et al. Sorafenib in advanced clear-cell renal-cell carcinoma. $N$ Engl J Med. 2007;356(2):125-134.

17. Sternberg CN, Davis ID, Mardiak J, et al. Pazopanib in locally advanced or metastatic renal cell carcinoma: results of a randomized phase III trial. J Clin Oncol. 2010;28(6):1061-1068.

18. Hudes G, Carducci M, Tomczak P, et al. Temsirolimus, interferon alfa, or both for advanced renal-cell carcinoma. $N$ Engl J Med. 2007;356(22):2271-2281.

19. Motzer RJ, Escudier B, Oudard S, et al. Efficacy of everolimus in advanced renal cell carcinoma: a double-blind, randomised, placebocontrolled phase III trial. Lancet. 2008;372(9637):449-456.

20. Escudier B, Pluzanska A, Koralewski P, et al. Bevacizumab plus interferon alfa-2a for treatment of metastatic renal cell carcinoma: a randomised, double-blind phase III trial. Lancet. 2007;370(9605):2103-2111.

21. Liu DQ, Chen TK, McGuire MA, Kord AS. Analytical control of genotoxic impurities in the pazopanib hydrochloride manufacturing process. J Pharm Biomed Anal. 2009;50(2):144-150.

22. Harris PA, Cheung M, Hunter RN 3rd, et al. Discovery and evaluation of 2-anilino-5-aryloxazoles as a novel class of VEGFR-2 kinase inhibitors. J Med Chem. 2005;48(5):1610-1619.
23. Harris PA, Boloor A, Cheung M, et al. Discovery of 5-[[4-[(2,3dimethyl-2 $H$-indazol-6-yl)methylamino]-2 pyrimidinyl]amino] 2 methylbenzenesulfonamide (pazopanib), a novel and potent vascular endothelial growth factor receptor inhibitor. J Med Chem. 2008;51(15):4632-4640.

24. Kumar R, Knick VB, Rudolph SK, et al. Pharmacokinetic-pharmacodynamic correlation from mouse to human with pazopanib, a multikinase angiogenesis inhibitor with potent antitumor and antiangiogenic activity. Mol Cancer Ther. 2007;6(7):2012-2021.

25. Hurwitz HI, Dowlati A, Saini S, et al. Phase I trial of pazopanib (GW786034), an oral multikinaseangiogenesis inhibitor, in patients with advanced cancer: results of safety, pharmacokinetics, and clinical activity. Clin Cancer Res. 2009;15(12):4220-4227.

26. Food and Drug Administration. Votrient ${ }^{\mathrm{TM}}$. Full prescribing information. October, 2009. Available from: http://www.accessdata. fda.gov/drugsatfda_docs/label/2009/022465lbl.pdf. Accessed July 23, 2011.

27. Ratain MJ, Eisen T, Stadler WM, et al. Phase II placebo-controlled randomized discontinuation trial of sorafenib in patients with metastatic renal cell carcinoma. J Clin Oncol. 2006;24(16):2505-2512.

28. Hutson TE, Davis ID, Machiels JH, et al. Efficacy and safety of pazopanib in patients with metastatic renal cell carcinoma. J Clin Oncol. 2010;28(3):475-480.

29. Sternberg CN, Hawkins RE, Szczylik C, et al. Randomized, double-blind phase III study of pazopanib in patients with advanced/metastatic renal cell carcinoma (MRCC): final overall survival (OS) results. Ann Oncol. 2010;21(Suppl 8):abstract LBA22.

30. Sternberg CN, Hawkins RE, Szczylik C, et al. A randomized, doubleblind phase III study (VEG105192) of pazopanib (paz) versus placebo (pbo) in patients with advanced/metastatic renal cell carcinoma (mRCC): updated safety results. J Clin Oncol. 2011;29(Suppl 7): abstract 313.

31. Rini BI, Halabi S, Rosenberg JE, et al. Phase III trial of bevacizumab plus interferon alfa versus interferon alfa monotherapy in patients with metastatic renal cell carcinoma: final results of CALGB 90206. J Clin Oncol. 2010;28(13):2137-2143.

32. Escudier B, Szczylik C, Hutson TE, et al. Randomized phase II trial of first-line treatment with sorafenib versus interferon alfa-2a in patients with metastatic renal cell carcinoma. J Clin Oncol. 2009;27(8):1280-1287.

33. Rini BI, Szczylik C, Tannir NM, et al. AMG 386 in combination with sorafenib in patients (pts) with metastatic renal cell cancer (mRCC): a randomized, double-blind, placebo-controlled, phase II study. J Clin Oncol. 2011;29(Suppl 7):abstract 309.

34. Motzer RJ, Hutson TE, Tomczak P, et al. Overall survival and updated results for sunitinib compared with interferon alfa in patients with metastatic renal cell carcinoma. J Clin Oncol. 2009;27(22):3584-3590.

35. Escudier B, Bellmunt J, Negrier S, et al. Phase III trial of bevacizumab plus interferon alfa- $2 \mathrm{a}$ in patients with metastatic renal cell carcinoma (AVOREN): final analysis of overall survival. J Clin Oncol. 2010; 28(13):2144-2150.

36. Rini BI, Halabi S, Rosenberg JE, et al. Bevacizumab plus interferon alfa compared with interferon alfa monotherapy in patients with metastatic renal cell carcinoma: CALGB 90206. J Clin Oncol. 2008;26(33):5422-5428.

37. McCann L, Amit O, Pandite L, Amado RG. An indirect comparison analysis of pazopanib versus other agents in metastatic renal cell carcinoma (mRCC). J Clin Oncol. 2010;28(Suppl):abstract e15128.

38. Escudier B, Eisen T, Stadler WM, et al. Sorafenib for treatment of renal cell carcinoma: final efficacy and safety results of the phase III treatment approaches in renal cancer global evaluation trial. J Clin Oncol. 2009;27(20):3312-3318.

39. Heng DY, Xie W, Bjarnason GA, et al. Progression-free survival as a predictor of overall survival in metastatic renal cell carcinoma treated with contemporary targeted therapy. Cancer. 2011;117(12): 2637-2642. 
40. Reeves JA, Spigel DR, Daniel DB, Friedman EK, Burris HA, Hainsworth JD. Pazopanib in patients with metastatic renal cell carcinoma previously treated with sunitinib or bevacizumab: a Sarah Cannon Research Institute phase II trial. J Clin Oncol. 2011;29(Supp1):abstract 4659.

41. Matrana MR, Atkinson BJ, Corn PG, Jonasch E, Tannir NM. Metastatic renal cell carcinoma treated with pazopanib after progression on other targeted agents: a single-institution experience. J Clin Oncol. 2011;29(Suppl 7):abstract 351.

42. ClinicalTrials.gov. An open-label pharmacodynamic study of bevacivumab and pazopanib in renal cell carcinoma. Oct 8, 2009. Available from: http://clinicaltrials.gov/ct2/show/NCT00992121. Accessed June 22, 2011.

43. ClinicalTrials.gov. Pazopanib and everolimus in patients with advanced solid tumors and previously treated kidney cancer. Aug 17, 2010. Available from: http://clinicaltrials.gov/ct2/show/NCT01184326. Accessed June 22, 2011.

44. Semrad TJ, Eddings C, Dutia MP, Christensen S, Lau D, Lara P. Phase I study of temsirolimus (Tem) and pazopanib (Paz) in solid tumors with emphasis on renal cell carcinoma (RCC). J Clin Oncol. 2011;29(Suppl): abstract e15113.

45. Xu C, Bing NX, Ball HA, et al. Pazopanib efficacy in renal cell carcinoma: evidence for predictive genetic markers in angiogenesis-related and exposure-related genes. J Clin Oncol. 2011;29(18):2557-2564.

46. Xu C, Ball HA, Bing N, et al. Association of genetic markers in angiogenesis- or exposure-related genes with overall survival in pazopanib (P) treated patients (Pts) with advanced renal cell carcinoma. J Clin Oncol. 2011;29(Suppl 7):abstract 303.
47. Houk BE, Bello CL, Poland B, Rosen LS, Demetri GD, Motzer RJ Relationship between exposure to sunitinib and efficacy and tolerability endpoints in patients with cancer: results of a pharmacokinetic/ pharmacodynamic meta-analysis. Cancer Chemother Pharmacol. 2010;66(2):357-371.

48. Suttle B, Ball HA, Molimard M, et al. Relationship between exposure to pazopanib $(\mathrm{P})$ and efficacy in patients (pts) with advanced renal cell carcinoma (mRCC). J Clin Oncol. 2010;28(Suppl):abstract 3048.

49. ClinicalTrials.gov. Pazopanib versus sunitinib in the treatment of locally advanced and/or metastatic renal cell carcinoma (COMPARZ). July 22, 2008. Available from: http://clinicaltrials.gov/ct2/show/NCT00720941. Accessed June 22, 2011.

50. ClinicalTrials.gov. Patient preference study of pazopanib versus sunitinib in advanced or metastatic kidney cancer (PISCES). February 4, 2010. Available from: http://clinicaltrials.gov/ct2/show/NCT01064310. Accessed June 22, 2011.

51. Kapadia S, Hapani S, Wu S. Risk of high-grade liver toxicity with pazopanib in patients with cancer: a meta-analysis. J Clin Oncol. 2011;29(Suppl):abstract 4595 .

52. Pickard A, Cella D, Duh MS, et al. Health-related quality of life in patients with advanced renal cell carcinoma receiving pazopanib or placebo in a randomized phase III trial. J Clin Oncol. 2011;29(Suppl): abstract 9096.

53. Coppin C, Porzsolt F, Awa A, Kumpf J, Coldman A, Wilt T. Immunotherapy for advanced renal cell cancer. Cochrane Database Syst Rev. 2005;1:CD001425.
Cancer Management and Research

\section{Publish your work in this journal}

Cancer Management and Research is an international, peer-reviewed open access journal focusing on cancer research and the optimal use of preventative and integrated treatment interventions to achieve improved outcomes, enhanced survival and quality of life for the cancer patient The journal welcomes original research, clinical \& epidemiological

\section{Dovepress}

studies, reviews \& evaluations, guidelines, expert opinion \& commentary, case reports \& extended reports. The manuscript management system is completely online and includes a very quick and fair peerreview system, which is all easy to use. Visit http://www.dovepress.com/ testimonials.php to read real quotes from published authors. 